\title{
Cuerpo y procesos de modernización en África. El caso de Guinea Ecuatorial
}

\author{
Jaume Vallverdú Vallverdú
}

El que es presenta tot seguit és un projecte de recerca collectiu $\mathrm{R}+\mathrm{D}$ que es desenvolupa des del primer de gener del 2012 fins al 31 de desembre del 2014. Dirigit pel Dr. Josep Martí Pérez, de la Institució Milà i Fontanals del CSIC amb seu a Barcelona, l'integra un total de sis investigadors que es distribueixen les tasques i temàtiques de recerca de la manera següent: Josep Martí, presentació social del cos; Begonya Enguix, qüestions de gènere; Laura Porzio, grups d'edat; Virgínia Forns, adscripcions ètniques a Guinea Equatorial; Jacint Creus, dimensió diacrònica, i Jaume Vallverdú, processos de modernització i diàspora.

La seva matriu prové de dues vies. D'una banda, un grup originari de treball sobre antropologia del cos constituït l'any 2007 al voltant de l'Institut Català d'Antropologia, amb l'objectiu de treballar bàsicament sobre la problemàtica del cos com a construcció simbòlica, com a objecte de presentació i com a objecte de representació. ${ }^{1}$ I, de l'altra, un projecte de recerca precedent del qual l'actual nés la continuació: "La presentación social del cuerpo en el contexto de la globalización y la multiculturalidad”, amb el mateix investigador principal, ${ }^{2}$ finançat entre els anys 2007 i 2010 dins del Plan Nacional de Investigación Científica, Desarrollo e Innovación Tecnológica i amb uns resultats concrets. ${ }^{3}$

L'objectiu genèric d'aquest projecte previ fou analitzar les formes contemporànies de presentació social del cos en un context social caracteritzat — tal com indica el subtítol - pel multiculturalisme, els processos de globalització i les

1. Els integrants originals d'aquest grup eren els següents: Josep Martí, Yolanda Aixalà, Elisenda Ardèvol, Diana Sarkis, Araceli Muñoz, Susan DiGiacomo, Begonya Enguix, José Luis Rodríguez, Julieta Vartabedian, Àngel Martínez i Jaume Vallverdú.

2. Acompanyat en aquest cas per Elisenda Ardèvol, Yolanda Aixalà, Begonya Enguix, Manuel Mandianes i Jaume Vallverdú.

3. En l'àmbit individual en forma de publicacions personals diverses, i en el colllectiu: organització del Congrés El Cuerpo: Objeto y Sujeto de las Ciencias Humanas y Sociales, coordinat per Josep Martí i Yolanda Aixalà i cel.lebrat a Barcelona (seu del CSIC), del 28 al 31 de gener del 2009, amb contribucions d'alguns dels membres de l'equip de recerca aleshores participant. Així mateix, la preparació de dos dossiers/monogràfics colllectius: "La presentació social del cos", Quaderns de l'Institut Català d'Antropologia, núm. 26, 2011, i "La presentación social del cuerpo en el contexto de la globalización y la multiculturalidad", Revista de Dialectología y Tradiciones Populares (en premsa, 2012). 
tensions de redefinició o afirmació de les identitats locals. En aquest marc, s'ha volgut estudiar la negociació de la identitat a través de la presentació corporal pública i explorant quatre àmbits molt concrets:

1. Globalització, modificacions corporals i identitat. El propòsit més concret en aquest nivell ha estat obtenir una visió actualitzada de les actituds i pràctiques de la població de la nostra societat relatives a les modificacions corporals, tractant en especial el tatuatge i el pírcing a la ciutat de Barcelona i la seva rellevància en termes socials i identitaris.

2. L'escenificació de la diferència cultural: negociació de la identitat a través de la presentació pública del cos. El cas de la població d'origen magrebí. L'objectiu específic en aquest àmbit ha estat estudiar la presentació pública del cos tal com es produeix entre el colllectiu magrebí a la nostra societat i investigar al mateix temps com influeix l'aspecte corporal i la indumentària en la percepció del migrant magrebí.

3. Els limits de la privacitat: la presentació del cos a l'espai públic d'Internet. En aquest nivell s'han volgut analitzar de forma singular les pràctiques de representació del cos, especialment aquelles vinculades a la presentació més pròpia i personal, tal com es manifesten al mitjà del ciberespai.

4. El testimoni corporal: la construcció de la identitat collectiva a través de la presentació pública del cos en nous grups religiosos. Àmbit que s'ha centrat particularment en l'estudi dels processos de gestió ideològica, simbòlica i ritual del cos a partir de sistemes religiosos (moviment Hare Krishna, evangèlics pentecostals) que remarquen l'emoció i l'expressió corporal com a vehicles essencials per a l'experiència religiosa, i en els quals tot allò relacionat amb el cos té especial rellevància pel que fa a la construcció de la identitat personal, social i religiosa.

Girant al voltant d'aquests grans àmbits, el projecte de recerca esmentat ha pretès així mateix contribuir a l'elaboració d'un marc teòric general de l'antropologia del cos. I sobre aquesta plataforma àmplia, la nova proposta de recerca té una orientació més focalitzada en els plànols ètnic i pròpiament empíric.

"Cos i processos de modernització a Àfrica. El cas de Guinea Equatorial" és, doncs, un projecte que té com a propòsit principal incrementar els coneixements sobre la dinàmica tradició-modernitat en el context del país africà re- 
ferenciat. Es parteix igualment de la idea que el cos juga un paper central per a la relació individu/societat, en especial pel que fa a aspectes d'identitat tant individuals com colllectius, però també d'agència humana sobre les estructures socials. Per això, l'estudi de la presentació social del cos en una societat determinada és molt significatiu per a la comprensió de la conceptualització i manifestació de la modernitat en aquesta societat. La recerca del projecte es desenvoluparà tant a Guinea Equatorial com entre la població immigrada guineoequatoriana resident a Catalunya, i caldrà així mateix tenir en compte el paper que la diàspora exerceix en la percepció i implementació de la modernitat en aquest país africà.

Sobre aquesta base, es tenen en compte tres grans àmbits d'actuació: a) la realitat actual a Guinea Equatorial, b) la realitat actual entre guineans a l'emigració i c) la tradició, amb interès especial per la percepció o visió que els propis agents socials en tenen ("invenció de la tradició").

Els objectius més específics del projecte són els següents:

1. Recopilar dades (tècniques, ús, significat) sobre les pràctiques relacionades amb la presentació social del cos entre la població guineoequatoriana (al seu país i a Espanya). Concretament: cura general del cos, indumentària i modificacions corporals. Es reuniran dades relatives a l'actualitat, al passat recent i a la percepció actual del passat ("tradició", "invent de la tradició").

2. Estudiar com es percep l'experiència local de la modernitat a través de la presentació social del cos.

3. Reflexionar sobre quin és el paper de la diàspora guineoequatoriana en la percepció local de la modernitat i en els processos de modernització en general de Guinea Equatorial. I estudiar com es reflecteix tot això en la presentació social del cos.

4. Analitzar quin paper juga la presentació social del cos en la percepció/ construcció d'unitats socials més extenses que les tradicionals.

5. Estudiar com s'instrumentalitza la presentació social del cos per part de les noves elits per reforçar la seva posició privilegiada.

6. Esbrinar quina relació podem establir entre l'experiència de la modernitat i la formació de subjectivitats individuals i col-lectives a partir de la presentació social del cos, amb especial atenció a les problemàtiques de gènere i etnicitat. 
7. Descobrir quins són els conflictes que es generen dins de la dialèctica tradició-modernitat i com es resolen.

8. Examinar fins a quin punt les categories dicotòmiques de la modernitat a través de la presentació social del cos valoren o estigmatitzen determinats segments de la població.

Pel que fa a la metodologia, la previsió per a la recollida de dades sorganitza, d'una banda, a partir de la cerca i l'ús de fonts bibliogràfiques i documentals i, de l'altra, a través del treball empíric.

En el primer àmbit, a més de les fonts bibliogràfiques pertinents per al projecte, part de les dades provindran del treball d'arxiu (entre d'altres, l'Archivo General de la Administración General del Estado, els dels missioners claretians que es troben tant a Guinea Equatorial — Luba - com a Espanya - Vic -) així com de publicacions actuals com ara revistes populars guineanes, forums de debat a Internet, fonts televisives i d'altres procedents de l’àmbit audiovisual (videoclips musicals). Els materials d'interès que es puguin recopilar en aquest àmbit de la recerca se sotmetran a anàlisi del contingut i del discurs per part dels membres de l'equip de recerca.

Quant al vessant empíric, es planteja la metodologia de recerca de tipus qualitatiu pròpia del treball de camp. Les tasques etnogràfiques es duran a terme tant a Guinea Equatorial com, d'acord amb els objectius i el marc teòric, a Espanya entre la població guineoequatoriana emigrada. Es preveu l'ús de les tècniques de recerca pròpies del treball etnogràfic: l'observació, l'observació participant, les entrevistes en profunditat i, en menor grau i de forma molt puntual, les enquestes. També es preveu per a casos molt concrets la utilització de tècniques biogràfiques (com ara els itineraris corporals) i de la fotografia. 